\title{
40GB/S WDM-MULTICASTING WAVELENGTH CONVERSION FROM 160GB/S OTDM SIGNAL
}

\author{
Yoshinari Awaji, Tetsuya Miyazaki, Fumito Kubota \\ National Institute of Information and Communications Technology, 4-2-1 Nukuikita, Koganei, \\ 184-8795 Tokyo, Japan: yossy@nict.go.jp
}

Abstract: We demonstrated a wavelength conversion experiment from $160 \mathrm{~Gb} / \mathrm{s}$ :OTDM signal to $4 \lambda \times 40 \mathrm{~Gb} / \mathrm{s}$ :WDM signals with multicasting function by using four-wave mixing in a highly-nonlinear fiber. This technique was based on the OTDM/WDM converter using FWM and the multicasting function is easily available by aligning mutual timing of WDM clock pulses.

\section{INTRODUCTION}

Multi-channel OTDM de-multiplexers are indispensable for a practical implementation of OTDM networks. The multi-channel de-multiplexers can be classified two categories. One is a combination of several optical gate switches and splitters, which needs a lot of components [1-2]. Another type utilizes a parametric process between OTDM signal and multi-color clock pulses by using single nonlinear medium. This type can be also considered as OTDM/WDM converter. Several investigations about such converter have been reported [3-5]. We demonstrated $160 / 4 \times 40 \mathrm{~Gb} / \mathrm{s}$ :OTDM/WDM converter by using four-wave mixing (FWM) in response to the increase of channel rate up to $40 \mathrm{~Gb} / \mathrm{s}$, either [6].

By the way, considering a border node between OTDM network and WDM network, conventional OTDM/WDM gateway offers an aggregation function of peer to peer data links. For example, a communication channel assigned to one of tributary channel within OTDM signal is assigned to a specific wavelength path uniquely, and only one WDM port can receive a specific tributary channels. On the other hand, multicasting function of node can deliver same information to several wavelength paths, simultaneously. In this report, we demonstrated the 
160/40Gb/s:OTDM/WDM converter with WDM-multicasting function, for the first time. It is able to supply higher functionality to OTDM/WDM gateway.

\section{EXPERIMENT}

\subsection{Basic concept}

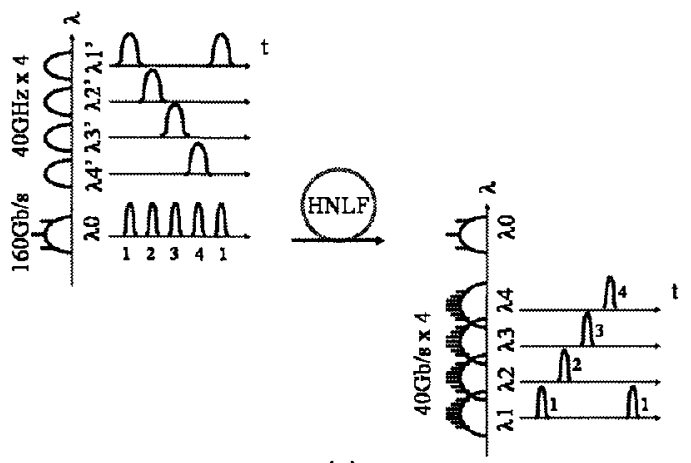

(a)

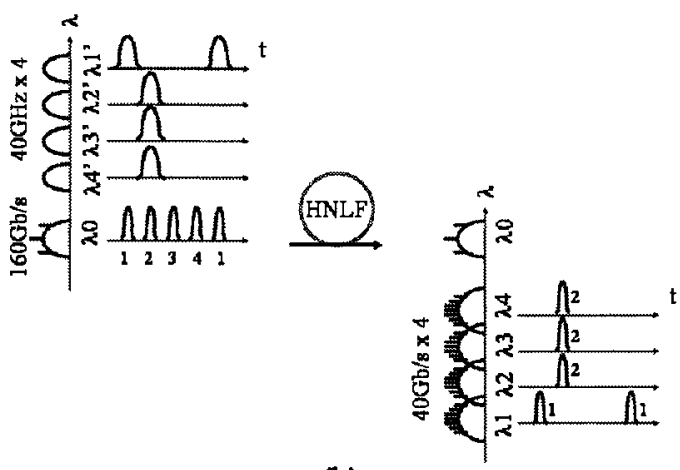

(b)

Figure 1. Proposed OTDM/WDM converter

(a) OTDM/WDM converter, full-DEMUX

(b) OTDM/WDM converter, multicasting 
Figure 1 shows the principle of proposed OTDM/WDM converter. A 160Gb/s OTDM signal acts as pump light of FWM. $40 \mathrm{GHz}$ clock pulses on four wavelengths were wavelength-converted to four $40 \mathrm{~Gb} / \mathrm{s}$ data on different wavelength-channels as a result of FWM in highly-nonlinear fiber (HNLF). If four clock pulses are overlapped on each tributary channels of $160 \mathrm{~Gb} / \mathrm{s}$ :OTDM signal one-on-one, it can be said as full de-multiplexing or OTDM/WDM full-conversion (Fig. 1(a)). However, if some of clock pulses have same timing, the corresponding wavelength-channels share same information simultaneously (Fig. 1(b)). This multicasting configuration is easily changed simply by moving the clock pulse timing. That is to say, a wavelength channel can request to connect with a specific tributary channel ignoring the other wavelengths channels. This flexibility can be realized by using individual clock pulses in contrast with the configuration using single chirped pulse [3].

A pulse width of clock pulses have to be less than OTDM time slot $(6.25 \mathrm{ps} @ 160 \mathrm{~Gb} / \mathrm{s})$ to suppress an interchannel crosstalk come from neighbouring tributary channels, hence FWM between clock pulses on same time slot can interfere each other. Incidentally, the FWM interference between clock pulses was negligible for the full de-multiplexing condition (Fig. 1(a)) in previous experiment [6] because the each clock pulses on four wavelengths occupied time slots exclusively. Reducing the peak power of clock pulses is important issue to overcome the crosstalk. We demonstrated the worst case in following experiment. That is, all the clock pulses located at same time slot and one of tributary channel was distributed to four wavelengths. This condition can also be considered as broadcasting. Any channel number of multicasting, e.g. Fig. 1(b), can be easily obtained from following results and our previous work [6].

\subsection{Setup and results}

Figure 2 shows an experimental setup. A mode-locked laser diode (MLLD) oscillating at $10 \mathrm{GHz}$ was launched into $2 \mathrm{~km}$ of dispersion-flattened fibre (DFF) to generate SC light. The pulse width and the center wavelength were $1.5 \mathrm{ps}$ and $1568 \mathrm{~nm}$, respectively. The average injected power was $20 \mathrm{~mW}$ (estimated as $1.3 \mathrm{~W}$ of peak power). Half of the SC light was quadrupled to generate $40 \mathrm{GHz}$ pulses using a PLC circuit and spectrum-slicing four wavelength channels at 1552.524 $1557.363 \mathrm{~nm}$ using a $200 \mathrm{GHz}$ spaced arrayed-waveguide-grating (AWG-1). The pass band of this AWG was $0.88 \mathrm{~nm}$ of Gaussian (FWHM). As a result of spectrum-slicing, the pulse width in every channel was $4.3 \mathrm{ps}$ with Gaussian fitting. These four lights were adjusted each timing and polarization as same. Another part of the SC light was filtered at $1546.12 \mathrm{~nm}$, modulated by $10 \mathrm{~Gb} / \mathrm{s}$ PRBS: $2^{7}-1$ data, and multiplexed up to $160 \mathrm{~Gb} / \mathrm{s}$ using a PLC multiplexer that had $200 \mathrm{ps}$ offset 
delays in each multiplexing segment to de-correlate the tributary channels. The bandwidth of this $160 \mathrm{~Gb} / \mathrm{s}$ light was adjusted by following cascaded $3 \mathrm{~nm}$ bandpass filters (BPFs) resulting in a pulse width of $2.8 \mathrm{ps}$. The residual chirp was compensated by the single-mode fibre (SMF).

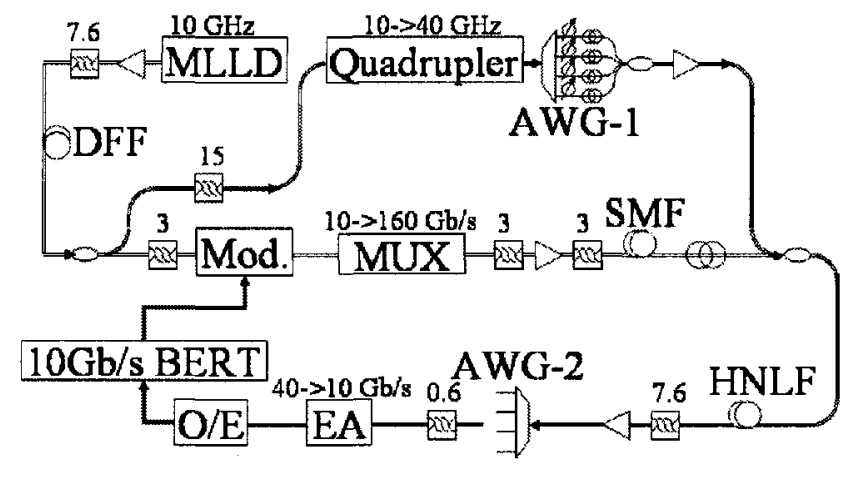

Figure 2. Experimental setup

The $160 \mathrm{~Gb} / \mathrm{s}$ light and four $40 \mathrm{GHz}$ lights were coupled and launched into $400 \mathrm{~m}$ of HNLF to cause FWM. The nonlinear coefficient was $11.8 \mathrm{~W}^{-1} \mathrm{~km}^{-1}$, the zero-dispersion wavelength was $1546.05 \mathrm{~nm}$, and the dispersion and dispersion slope at $1550 \mathrm{~nm}$ were $0.209 \mathrm{ps} / \mathrm{nm} / \mathrm{km}$ and $0.038 \mathrm{ps} / \mathrm{nm}^{2} / \mathrm{km}$, respectively. The average power of $160 \mathrm{~Gb} / \mathrm{s}$ and $4 \times 40 \mathrm{GHz}$ signals was +20 and $+10 \mathrm{dBm}$, respectively. The $4 \times 40 \mathrm{~Gb} / \mathrm{s}$ idler signals generated at $1535.036 \sim 1539.766 \mathrm{~nm}$ were filtered and spectrum-sliced using a 200GHz spaced AWG-2 (designated $\lambda 1 \sim \lambda 4$ ). To eliminate WDM-interchannel crosstalk, a $0.6 \mathrm{~nm}$ BPF was applied. We evaluated the bit error quality at a $10 \mathrm{~Gb} / \mathrm{s} \mathrm{BERT}$ set, hence we had to de-multiplex each $40 \mathrm{~Gb} / \mathrm{s}$ signal to $10 \mathrm{~Gb} / \mathrm{s}$ using an electro-absorption (EA) modulator after OTDM/WDM conversion.

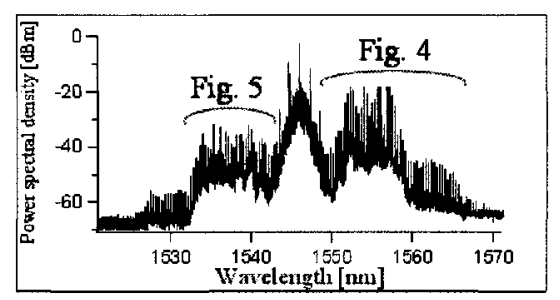

Figure 3. Spectral allocation

Center: $160 \mathrm{~Gb} / \mathrm{s}$ OTDM signal, Right: 4 x $40 \mathrm{GHz}$ clock, Left: $4 \lambda$ x $40 \mathrm{~Gb} / \mathrm{s}$ converted data 
Figure 3 shows the spectral allocation. The center peak was $160 \mathrm{~Gb} / \mathrm{s}:$ OTDM signal. In spite that the injected $160 \mathrm{~Gb} / \mathrm{s}$ signal into HNLF had restricted bandwidth due to the cascaded BPFs, the output $160 \mathrm{~Gb} / \mathrm{s}$ spectrum broadened because of intraband FWM. Four $40 \mathrm{GHz}$ clock pulses were located at longer wavelength than $160 \mathrm{~Gb} / \mathrm{s}$ signal, and the converted $40 \mathrm{~Gb} / \mathrm{s}$ signals were located at shorter wavelength. The magnified spectra are shown in Fig. 4 and 5, respectively. In Fig.4 (a), the spectra of input clock pulses on four wavelengths are shown in two different colors to distinguish the neighbouring spectra. Fig.4 (b) shows the FWM components occurred when clock pulses were injected into HNLF without $160 \mathrm{~Gb} / \mathrm{s}:$ OTDM signal. The spectral peak of FWM components caused by clock pulses were $-30 \mathrm{~dB}$ lower than the clocks itself due to the wider pulse width and lower average power than $160 \mathrm{~Gb} / \mathrm{s}$ pumping light.

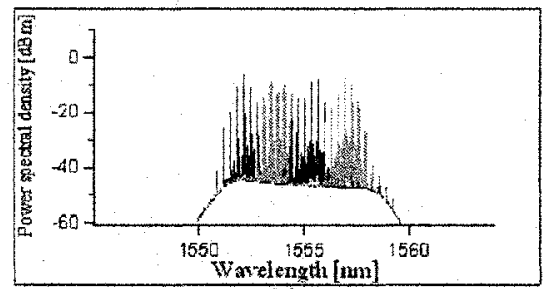

(a)

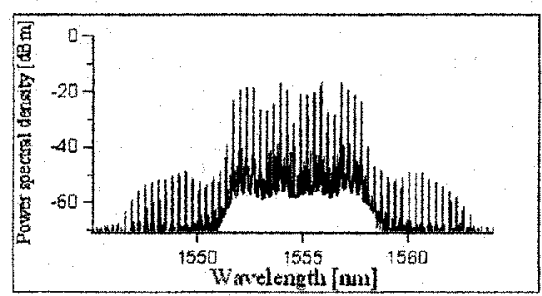

(b)

Figure 4. Spectra of clock pulses

(a) Input into HNLF

(b) Output from HNLF clock without $160 \mathrm{~Gb} / \mathrm{s}$ signal

Figure 5 shows spectra and waveforms of the converted $4 \lambda \times 40 \mathrm{~Gb} / \mathrm{s}$ signals. The solid lines on spectra represented the location of $0.6 \mathrm{~nm}$ BPF for every wavelength channels to eliminate the WDM interchannel crosstalk. The $40 \mathrm{~Gb} / \mathrm{s}$ waveforms were observed by optical sampling system. In spite of several causes of crosstalk, the eye opening was very clear. The variation of the pulse peak decreased when the timing of clock pulses were different (full de-multiplexing 
configuration), hence it must be caused by FWM interference between clock pulses. The clarification of this phenomenon is future issue.

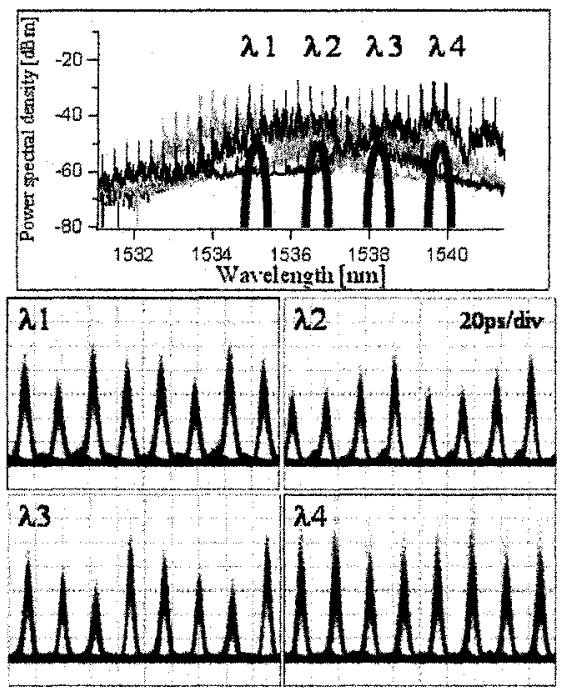

Figure 5. Spectra and waveforms of converted $4 \lambda \times 40 \mathrm{~Gb} / \mathrm{s}$ data

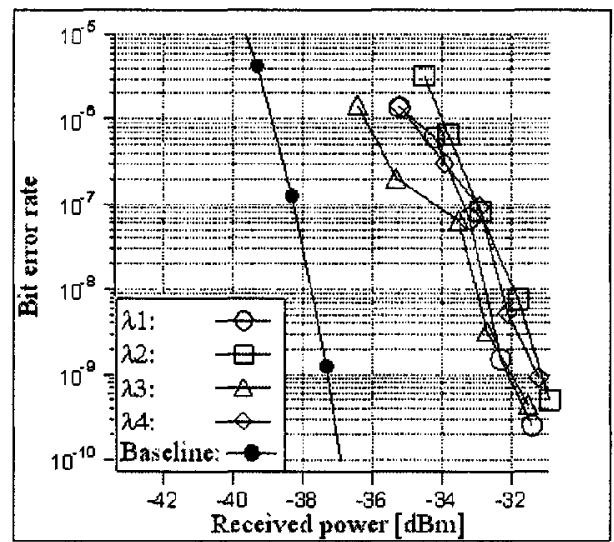

Figure 6. Measured bit error rates for the worst case

Finally, we measured bit error rates (BERs) at $10 \mathrm{~Gb} / \mathrm{s}$ as shown in Figure 6. We achieved the BER $<10^{-9}$ for every channel, and the worst cases of each wavelength channels and the $10 \mathrm{~Gb} / \mathrm{s}$ baseline were represented. The maximum MUX/DEMUX penalty was $-5.8 \mathrm{~dB}$. 


\section{CONCLUSIONS}

We successfully demonstrated the $40 \mathrm{~Gb} / \mathrm{s}$ WDM-multicasting from 160Gb/s:OTDM signal by using similar configuration with OTDM/WDM converter. The FWM interference between clock pulses surely affect the converted waveforms, however, the bit error rate were below $10^{-9}$ for every channel. In this experiment, we showed four wavelengths multicasting (broadcasting), and we have already shown the OTDM/WDM full-conversion [6]. Therefore, any combination of channel selection as like Figure 1(b) could be easily realized.

\section{ACKNOWLEDGMENTS}

The authors wish to thank Mr. H. Sumimoto for his support.

\section{REFERENCES}

[1] M. L. Dennis, W. I. Kaechele, W. K. Burns, T. F. Carruthers, I. N. Duling III, "Photonic serial-parallel conversion of high-speed OTDM data," IEEE Photon. Technol. Lett., vol. 12, pp. 1561-1563, November 2000.

[2] I. Shake, H. Takara, K. Uchiyama, I. Ogawa, T. Kitoh, T. Kitagawa, M. Okamoto, K. Magari, Y. Suzuki, T. Morioka, "160 Gbit/s full optical time-division demultiplexing using FWM of SOA-array integrated on PLC," IEE Electron. Lett., vol. 38, pp. 37-38, January 2002.

[3] K. Uchiyama, T. Morioka, "All-optical time-division demultiplexing experiment with simultaneous output of all constituent channels from 100Gbit/s OTDM signal," IEE Electron. Lett., vol. 37, pp. 642-643, May 2001.

[4] H. Sotobayashi, W. Chujo, K. Kitayama, "Photonic gateway: TDM-to-WDM-to-TDM conversion and reconversion at $40 \mathrm{Gbit} / \mathrm{s}$ (4 channels x $10 \mathrm{Gbits} / \mathrm{s})$," JOSA B., vol. 19, pp. 2810-2816, November 2002.

[5] L. Rau, W. Wang, B-E. Olsson, Y. Chiu, H-F. Chou, D. J. Blumenthal, J. E. Bowers, "Simultaneous all-optical demultiplexing of a 40-Gb/s signal to $4 \times 10 \mathrm{~Gb} / \mathrm{s}$ WDM channels using an ultrafast fiber wavelength converter," IEEE Photon. Technol. Lett., vol. 14, pp. 1725-1727, December 2002.

[6] Y. Awaji, T. Miyazaki, F. Kubota, “160/4x40Gb/s OTDM/WDM Conversion Using FWM Fibre," ECOC 2004, now submitting. 